\title{
Chemoprevention of mouse urinary bladder carcinogenesis by fermented brown rice and rice bran
}

\author{
TOSHIYA KUNO ${ }^{1}$, YOSHINOBU HIROSE $^{1}$, YASUHIRO YAMADA ${ }^{1}$, KAZUYA HATA $^{1}$, \\ SHENG HONG QIANG ${ }^{1}$, NAMI ASANO ${ }^{1}$, TAKERU OYAMA ${ }^{1}$, HUILAN ZHI ${ }^{1}$, \\ TERUAKI IWASAKI ${ }^{2}$, HIROSHI KOBAYASHI ${ }^{3}$ and HIDEKI MORI ${ }^{1}$ \\ ${ }^{1}$ Department of Tumor Pathology, Graduate School of Medicine, Gifu University, 1-1 Yanagido, Gifu 501-1194; \\ ${ }^{2}$ Genmai Koso Co., Ltd., Nishi 1-chome, Kita-ku, Sapporo 001-0012; ${ }^{3}$ Sapporo Cancer Seminar, \\ 6 Odori-Nishi, Chuo-ku, Sapporo 064-0820, Japan
}

Received September 15, 2005; Accepted November 15, 2005

\begin{abstract}
Fermented brown rice by Aspergillus oryzae (FBRA) has been shown to be a potent anti-carcinogenic compound. Here, we investigated the modifying effects of dietary feeding with a naturally occurring anti-oxidant FBRA on $\mathrm{N}$-butyl- $\mathrm{N}$-(4-hydroxybutyl)-nitrosamine (OH-BBN)induced urinary bladder carcinogenesis in male ICR mice. Five-week-old male ICR mice were divided into 7 groups, and groups 1-5 were given OH-BBN (500 ppm) in drinking water for 6 weeks starting at 7 weeks of age. Groups 2 and 3 were fed the diet containing 5\% and 10\% FBRA during the initiation phase, respectively, whereas groups 4 and 5 were fed these diets during the post-initiation phase. Group 6 was given the diet containing 10\% FBRA throughout the experiment, and group 7 was kept on the basal diet alone and served as an untreated control. At the end of the study (week 32), the incidences of simple hyperplasia, dysplasia and carcinoma in the bladders of group 1 (OH-BBN alone) were $92 \%, 49 \%$ and $38 \%$, respectively. Those of group $5(64 \%$, $23 \%$ and $10 \%$ ) and the incidence of carcinoma of group 4 $(17 \%)$ was significantly less than that of group 1. Furthermore, the multiplicity of simple hyperplasia and carcinoma of group 5 was significantly less than that of group 1. Postinitiation exposure of $10 \%$ FBRA significantly decreased the number/nucleus of silver-stained nucleolar organizer region proteins (AgNORs), an index of cell proliferation, in the
\end{abstract}

Correspondence to: Dr Toshiya Kuno, Department of Tumor Pathology, Graduate School of Medicine, Gifu University, 1-1 Yanagido, Gifu 501-1194, Japan

E-mail: fwkn4521@ybb.ne.jp

Abbreviations: FBRA, fermented brown rice by Aspergillus oryzae; $\mathrm{OH}-\mathrm{BBN}, \mathrm{N}$-butyl- $\mathrm{N}$-(4-hydroxybutyl)nitrosamine; AgNORs, silverstained nucleolar organizer region proteins

Key words: fermented brown rice, rice bran, urinary bladder cancer non-lesional transitional epithelium when compared to that of the control. Our results indicate that FBRA exerts chemopreventive effects against chemically induced urinary bladder carcinogenesis through anti-proliferative mechanisms. FBRA could be a promising chemopreventive agent for human urinary bladder cancer.

\section{Introduction}

Bladder cancer is the 7 th most common cancer worldwide, with an estimated 336,000 new cases occurring each year (1). In Japan, the incidence and mortality rates of this malignancy are lower compared with Western populations, but have gradually increased $(2,3)$. The occurrence of neoplasms in the urinary tract epithelium is known to relate to multistage and multifocal carcinogenesis. A high recurrence rate of superficial bladder tumors, even after curative transurethral resection, has often been reported (4). These successive, recurrent tumors may increase in their histological grade, and more than $15 \%$ of the patients are predicted to suffer the progression with subsequent poor prognosis $(5,6)$. A number of anticancer drugs have been used, mainly via local instillation into the bladder, as an adjuvant to surgery to suppress or prevent tumor recurrence. However, only a few drugs have been regarded as effective agents. Therefore, a new modality is required to achieve a more satisfactory clinical control of this malignancy.

One approach to curb cancer incidence is chemopreventive intervention through which the disease can be totally prevented, delayed, or fixed dormant by the administration of one or more naturally occurring and synthetic chemical agents. Certain synthetic compounds, such as oltipraz, piroxicam, indomethacin and $\mathrm{D}, \mathrm{L}-\alpha$-difluoromethylornithin, have been reported to have inhibitory effects on experimentally induced urinary bladder cancer models (7). Some natural compounds also inhibit chemically induced urinary bladder carcinogenesis $(8,9)$. Flavonoids are considered to be a rich source of chemopreventive agents, having various therapeutic biological activities that exert anti-inflammatory, anti-allergic, antiviral, anti-mutagenic, anti-proliferative and anti-oxidative properties (10). Some compounds of a scavenging activated 
oxygen species, in particular, exhibit chemopreventive effects (11).

Rice is one of the major cereal foods eaten as a staple by the worldwide population, especially in Asian countries. Rice seeds and rice germ contain fiber and several kinds of antioxidants, such as ferulic acid (12), phytic acid (13), tocopherols and oryzanols (14). Among them, vitamin E has the capacity to inhibit $N$-nitrosation. Due to these effects, it is regarded as a possible chemopreventive agent of bladder cancer. Lamm et al studied the effect of a megadose vitamin combination in a double-blind fashion (15). In bladder cancer, a significant protective effect is conferred by a high dose combination of vitamins A, B6, C and E. We reported the chemopreventive effects of rice germ alone and the compounds contained in rice bran or rice germ against carcinogenesis in the large bowel or tongue of rats $(16,17)$. Fermented brown rice by Aspergillus oryzae (FBRA) is a processed food prepared by fermenting brown rice and rice bran with Aspergillus oryzae. We previously reported that FBRA has inhibitory effects on carcinogenesis of the colon, liver, and esophagus in rodents (18-20). It is already known that FBRA acts as a potent-free radical scavenger (21). Tobacco smoking and occupational exposure are major risk factors of bladder cancer via exposure to polycyclic aromatic hydrocarbons and aromatic amines, which lead to oxidative stress and DNA damage. Antioxidants have the potential to neutralize the harmful effects of DNA-damaging free radicals, such as those produced by smoking, and these nutrients have been regarded as protective factors for urinary bladder cancer.

In the present study, we investigated the chemopreventive potential of FBRA during the initiation and post-initiation stages on $N$-butyl- $N$-(4-hydroxybutyl)-nitrosamine $(\mathrm{OH}$ $\mathrm{BBN}$ )-induced bladder carcinogenesis in male ICR mice. In addition, the effect of FBRA on cell proliferation activity in the bladder epithelium was examined to elucidate the underlying mechanism.

\section{Materials and methods}

Animals, diets, carcinogen and FBRA. Male 4-week-old ICR mice were purchased from Japan SLC, Inc. (Hamamatsu). After a 1-week quarantine, the mice were transferred to a holding room under controlled conditions of $23 \pm 2{ }^{\circ} \mathrm{C}$, $50 \pm 10 \%$ humidity, and a 12-h light/dark cycle. Powdered CE-2 (Clea Japan, Inc., Tokyo) was used as the basal diet for the experiment, and $\mathrm{OH}-\mathrm{BBN}$ was obtained from Tokyo Chemical Industry Co., Ltd. (Japan). The experimental diets were prepared by mixing $5 \%$ or $10 \%$ FBRA with the CE-2 diet, and all diets were stored in a cold room $\left(4^{\circ} \mathrm{C}\right)$ and freely available to the animals. FBRA was supplied by Genmai Koso Co., Ltd. (Sapporo, Japan); its manufacturing process and composition were described previously (18).

Experimental procedure. A total of 222 mice were randomized into 7 groups as shown in Fig. 1. At 7 weeks of age, mice in groups 1- 5 received OH-BBN in drinking water for 6 weeks. Mice in groups 2 and 3 were given a diet containing 5\% and $10 \%$ FBRA for 8 weeks, respectively, starting 1 week before $\mathrm{OH}-\mathrm{BBN}$ exposure until the end of week 8 . They were then

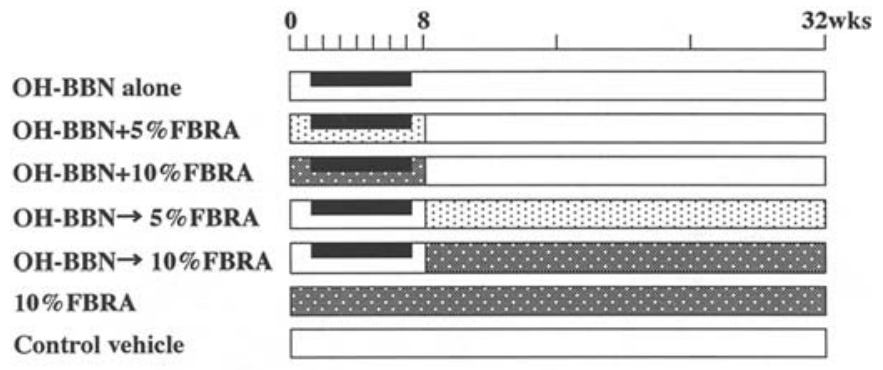

Basal diet and tap water $500 \mathrm{ppm}$ OH-BBN in drinking water $5 \%$ or $10 \%$ FBRA in basal diet

Figure 1. The experimental design

switched to and maintained on the basal diet until termination. Starting 1 week after the cessation of OH-BBN treatment, rats in groups 4 and 5 were fed the diet mixed with 5\% and $10 \%$ FBRA, respectively, and continued until termination. Mice in group 6 were fed the diet containing 10\% FBRA during the experiment. Mice in group 7 were given the basal diet and tap water throughout the experiment and served as controls.

All mice were carefully inspected daily, and consumption of the experimental diets mixed with the test compound was recorded to estimate dietary intake. The experiment was terminated after 32 weeks, and all animals were sacrificed to evaluate the frequency of preneoplastic and neoplastic lesions in the urinary bladder. At autopsy, the urinary bladders of all mice were inflated with $10 \%$ buffered formalin, fixed overnight in $10 \%$ buffered formalin, bisected longitudinally, inspected for gross lesions, then embedded in paraffin for histopathological evaluation on hematoxylin and eosin (H\&E)-stained sections. Proliferating lesions observed in the urinary bladder were histopathologically classified as: simple hyperplasia, epithelium of more than four layers demonstrating diffusely elevated proliferation; dysplasia, small lesions with severe cellular atypia as in carcinomas and mitosis but not invading the submucosa; and papilloma, without severe anaplasia, characterized by massive upward growth into the lumen supported by small vessels and fibrous connective tissues (Fig. 2). Carcinomas were classified into transitional cell carcinoma (TCC) and squamous cell carcinoma (SCC) (22). The liver and kidney were fixed with $10 \%$ formalin, embedded in paraffin blocks and processed routinely for histopathological examination.

Determination of cell proliferative activity by AgNORs. To assess the proliferative activity of non-lesional or normal urinary bladder epithelium, the number of AgNORs per nucleus was quantified according to methods described previously (23). The urinary bladder was removed, fixed in $10 \%$ buffered formalin, embedded in paraffin wax, and sliced into two serial sections ( $3 \mu \mathrm{m}$ in thickness). On one section, AgNOR staining was carried out using a 1-step silver colloid method. The AgNORs were visualized as distinct black dots, and the number of discrete dots and dot aggregates were counted on 100 nuclei of various lesions and non-lesional areas using a microscope with a $\times 400$ magnification. AgNORs that were aggregated and inseparable or clustered were 


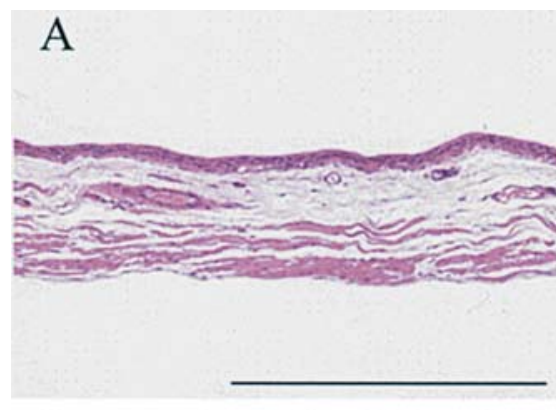

D

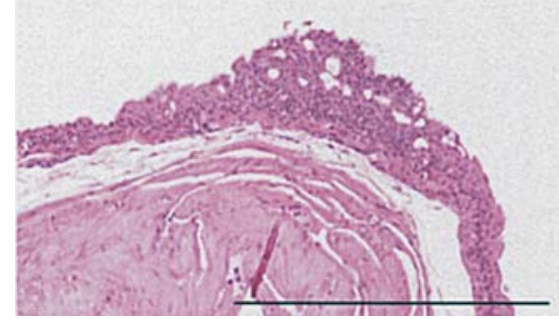

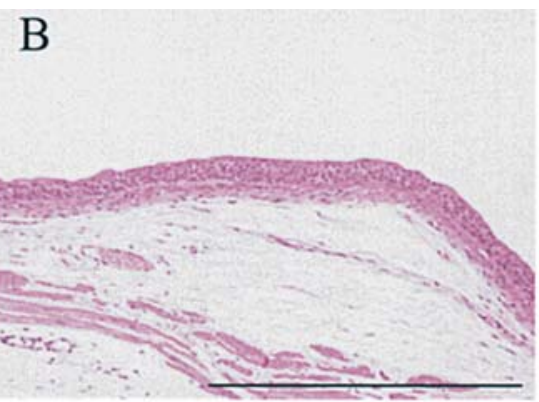

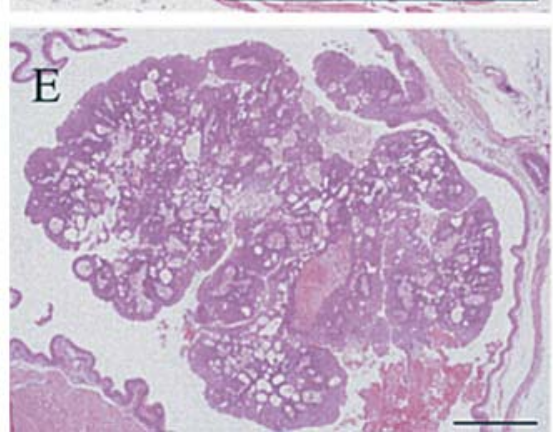

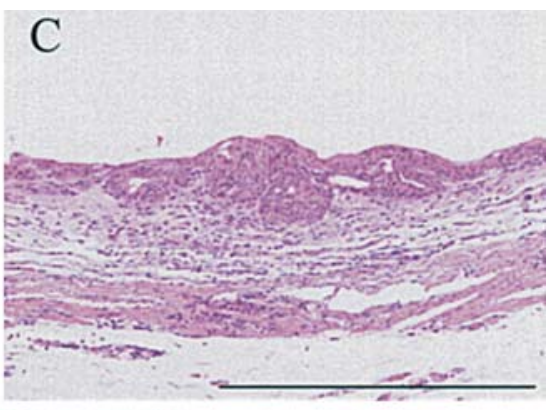

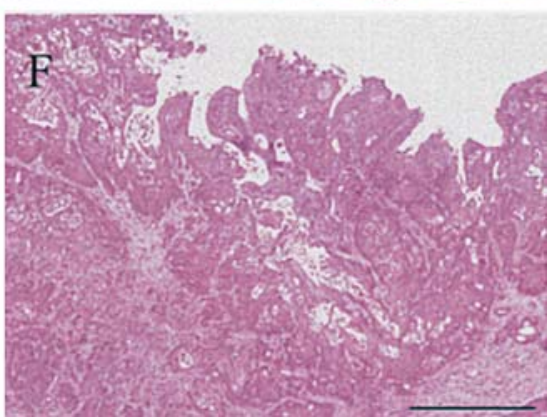

Figure 2. Histopathological representation of OH-BBN-induced tumorigenesis in the mouse urinary bladder (bar, $500 \mu \mathrm{m}$ ). (A) Photomicrograph of an H\&Estained normal mouse urinary bladder. (B) Simple hyperplasia, uniform increase in thickness of transitional cell lining. (C) Nodular hyperplasia, proliferating transitional cells arranged in solid round or oval islands. (D) Dysplasia, small lesions with severe cellular atypia as in carcinomas and mitosis but not invading the submucosa. (E) Papilloma, without severe anaplasia, characterized by massive upward growth into the lumen supported by small vessels and fibrous connective tissues. (F) Carcinoma, invasion through the basal lamina.

Table I. Body, liver and kidney weights of mice in each group.

\begin{tabular}{llcccc}
\hline Group & Treatment & $\begin{array}{c}\text { No. of } \\
\text { mice examined }\end{array}$ & Body weight $(\mathrm{g})$ & Liver weight $(\mathrm{g})$ & Kidney weight $(\mathrm{g})$ \\
\hline 1 & OH-BBN & 39 & $49.6 \pm 4.2^{\mathrm{a}}$ & $2.59 \pm 0.40$ & $0.93 \pm 0.14$ \\
2 & OH-BBN + 5\% FBRA & 38 & $50.0 \pm 11.0$ & $2.70 \pm 0.39$ & $0.95 \pm 0.16$ \\
3 & OH-BBN + 10\% FBRA & 35 & $53.9 \pm 8.4$ & $2.56 \pm 0.34$ & $0.94 \pm 0.18$ \\
4 & OH-BBN $\rightarrow 5 \%$ FBRA & 37 & $50.6 \pm 4.2$ & $2.60 \pm 0.31$ & $1.03 \pm 0.23$ \\
5 & OH-BBN $\rightarrow 10 \%$ FBRA & 39 & $49.9 \pm 5.5$ & $2.60 \pm 0.31$ & $1.01 \pm 0.20$ \\
6 & $10 \%$ FBRA alone & 17 & $52.4 \pm 7.4$ & $2.64 \pm 0.44$ & $1.03 \pm 0.26$ \\
7 & Control vehicle & 17 & $54.8 \pm 9.4$ & $2.77 \pm 0.51$ & $1.04 \pm 0.16$ \\
\hline
\end{tabular}

${ }^{\mathrm{a}}$ Mean $\pm \mathrm{SD}$.

considered as one structure. The highest number of AgNOR dots visible within a nucleus by focusing the microscope though the nucleus was counted. The mean number of AgNORs per nucleus was then calculated for each specimen. The remaining section was stained with $\mathrm{H} \& \mathrm{E}$ for histopathological diagnosis.

Statistical analysis. Statistical analysis of the incidence of lesions was performed using Fisher's exact probability test, and the data on body weight, liver weight, kidney weight, multiplicity and AgNORs were compared by one-factor ANOVA. The results were considered statistically significant if the P-value was $<0.05$.

\section{Results}

General observations. The oral administration of OH-BBN was well tolerated by all mice in groups $1-7$. There were no significant differences in the mean intake of OH-BBN or food among groups 1-5. The mean intake of food was constant and similar among the different groups during the entire treatment period. The mean body, liver, and kidney weights at the end of the study are indicated in Table I. Although the mean kidney weights in groups 4, 5 and 7 were larger than those of group 1, statistical significance was not found among the groups. There were no toxicopathological findings in the liver and kidney of any rat examined.

Incidence of tumors and pre-cancerous lesions. Hyperplasia, pre-cancerous lesions (dysplasia), transitional cell papillomas, or carcinomas developed in the urinary bladders of mice in groups 1-5. The incidence of these lesions in each group is shown in Table II. In group 1 (OH-BBN alone), the incidence of transitional cell papilloma and carcinoma was $13 \%$ (5/39 mice) and 38\% (15/39 mice) respectively. On the other hand, only a few mice given the test compound 
Table II. Incidence of pathological lesions in the urinary bladder.

No. of mice $(\%)$ with

\begin{tabular}{|c|c|c|c|c|c|c|c|}
\hline Group & Treatment & $\begin{array}{c}\text { No. of } \\
\text { mice examined }\end{array}$ & $\begin{array}{c}\text { Simple } \\
\text { hyperplasia }\end{array}$ & $\begin{array}{c}\text { Nodular } \\
\text { hyperplasia }\end{array}$ & Dysplasia & Papilloma & Carcinoma $^{\mathrm{a}}$ \\
\hline 1 & $\mathrm{OH}-\mathrm{BBN}$ & 39 & $36(92)$ & $24(62)$ & $19(49)$ & $5(13)$ & $15(38)$ \\
\hline 2 & $\mathrm{OH}-\mathrm{BBN}+5 \%$ FBRA & 38 & $32(84)$ & $22(58)$ & $17(45)$ & $5(13)$ & $9(24)$ \\
\hline 3 & OH-BBN + 10\% FBRA & 35 & $29(83)$ & $21(60)$ & $12(34)$ & $7(20)$ & $8(23)$ \\
\hline 4 & $\mathrm{OH}-\mathrm{BBN} \rightarrow 5 \%$ FBRA & 37 & $29(78)$ & $20(56)$ & $13(36)$ & $5(14)$ & $6(17)^{b}$ \\
\hline 5 & $\mathrm{OH}-\mathrm{BBN} \rightarrow 10 \% \mathrm{FBRA}$ & 39 & $25(64)^{c}$ & $16(41)$ & $9(23)^{b}$ & $5(13)$ & $4(10)^{\mathrm{c}}$ \\
\hline 6 & $10 \%$ FBRA alone & 17 & $0(0)$ & $0(0)$ & $0(0)$ & $0(0)$ & $0(0)$ \\
\hline 7 & Control vehicle & 17 & $0(0)$ & $0(0)$ & $0(0)$ & $0(0)$ & $0(0)$ \\
\hline
\end{tabular}

${ }^{\mathrm{a}}$ Carcinoma includes both transitional cell carcinoma and squamous cell carcinoma. ${ }^{\mathrm{b}}$ Significantly different from group 1 ( $\left.\mathrm{P}<0.05\right)$. ${ }^{\mathrm{c}}$ Significantly different from group $1(\mathrm{P}<0.01)$.

Table III. Multiplicity of pathological lesions in the urinary bladder.

\begin{tabular}{llcccccc}
\hline & & & \multicolumn{3}{c}{ Multiplicity } \\
\cline { 5 - 8 } Group & Treatment & $\begin{array}{c}\text { No. of } \\
\text { mice examined }\end{array}$ & $\begin{array}{c}\text { Simple } \\
\text { hyperplasia }\end{array}$ & $\begin{array}{c}\text { Nodular } \\
\text { hyperplasia }\end{array}$ & Dysplasia & Papilloma $^{\text {Carcinoma }}$ \\
\hline 1 & OH-BBN & 39 & $0.92 \pm 0.27^{\mathrm{b}}$ & $0.97 \pm 1.04$ & $0.82 \pm 1.30$ & $0.21 \pm 0.61$ & $0.62 \pm 0.94$ \\
2 & OH-BBN + 5\% FBRA & 38 & $0.84 \pm 0.37$ & $0.89 \pm 0.89$ & $0.66 \pm 0.88$ & $0.26 \pm 0.89$ & $0.34 \pm 0.67$ \\
3 & OH-BBN + 10\% FBRA & 35 & $0.83 \pm 0.38$ & $0.69 \pm 0.63$ & $0.83 \pm 1.46$ & $0.31 \pm 0.72$ & $0.34 \pm 0.73$ \\
4 & OH-BBN $\rightarrow 5 \%$ FBRA & 37 & $0.76 \pm 1.44$ & $0.89 \pm 1.07$ & $0.57 \pm 1.12$ & $0.30 \pm 0.94$ & $0.24 \pm 0.55$ \\
5 & OH-BBN $\rightarrow 10 \%$ FBRA & 39 & $0.64 \pm 0.47^{\mathrm{c}}$ & $0.54 \pm 0.76$ & $0.28 \pm 0.60$ & $0.21 \pm 0.61$ & $0.10 \pm 0.31^{\mathrm{d}}$ \\
\hline
\end{tabular}

${ }^{\mathrm{a} C a r c i n o m a ~ i n c l u d e s ~ b o t h ~ t r a n s i t i o n a l ~ c e l l ~ c a r c i n o m a ~ a n d ~ s q u a m o u s ~ c e l l ~ c a r c i n o m a . ~}{ }^{\mathrm{b}}$ Mean $\pm \mathrm{SD}$. ${ }^{\mathrm{c} S i g n i f i c a n t l y ~ d i f f e r e n t ~ f r o m ~ g r o u p ~} 1$ $(\mathrm{P}<0.05)$. ${ }^{\mathrm{d}}$ Significantly different from group $1(\mathrm{P}<0.01)$.

Table IV. Mean number of AgNORs/nucleus counts in the normal and non-lesional epithelium of the bladder.

\begin{tabular}{llccc}
\hline Group & Treatment & No. of mice examined & Normal & Non-lesional area \\
\hline 1 & OH-BBN & 39 & ND & $2.34 \pm 0.32^{\mathrm{a}}$ \\
2 & OH-BBN + 5\% FBRA & 38 & ND & $2.26 \pm 0.27$ \\
3 & OH-BBN + 10\% FBRA & 35 & ND & $2.22 \pm 0.24$ \\
4 & OH-BBN $\rightarrow 5 \%$ FBRA & 37 & ND & $2.23 \pm 0.30$ \\
5 & OH-BBN $\rightarrow 10 \%$ FBRA & 39 & ND & $2.13 \pm 0.20^{\mathrm{b}}$ \\
6 & $10 \%$ FBRA alone & 17 & $1.93 \pm 0.25$ & ND \\
7 & Control vehicle & 17 & $2.05 \pm 0.23$ & ND \\
\hline
\end{tabular}

${ }^{\mathrm{a}}$ Mean $\pm \mathrm{SD}$. ${ }^{\mathrm{b} S i g n i f i c a n t l y ~ d i f f e r e n t ~ f r o m ~ g r o u p ~} 1(\mathrm{P}<0.01)$. ND, not determined.

after $\mathrm{OH}-\mathrm{BBN}$ exposure, developed carcinomas (17\% in group 4 and $10 \%$ in group 5). These incidence rates were significantly smaller than those of group $1(\mathrm{P}<0.05$ and 0.01 , respectively). No neoplasms developed in the animals of groups 6 and 7 .

As for transitional cell hyperplasia (simple hyperplasia and nodular hyperplasia), the incidence in group 1 was $92 \%$ with simple hyperplasia and $62 \%$ with nodular hyperplasia. The incidence of simple hyperplasia in group 5 was significantly smaller than that of group $1(\mathrm{P}<0.01)$. The incidence of precancerous lesions (dysplasia) in group 1 was $49 \%$. The frequency of dysplasia in group $5(23 \%)$ was significantly lower than that of group $1(\mathrm{P}<0.05)$.

Multiplicity of tumors and pre-cancerous lesions. The multiplicity (number of tumors/rat) of urinary bladder neoplasms and those of preneoplastic lesions are shown in Table III. The urinary bladder tumors were solitary or 
multiple lesions of variable sizes and randomly distributed. The multiplicity of simple hyperplasia and transitional cell carcinoma of group $5(0.64 \pm 0.47$ and $0.10 \pm 0.31)$ was significantly smaller than that of group $1(0.92 \pm 0.27$ and $0.62 \pm 0.94)$.

AgNOR enumeration. Results of the morphometric analysis of AgNORs are summarized in Table IV. The mean AgNOR values in the non-lesional epithelium of the group exposed to $\mathrm{OH}-\mathrm{BBN}$ alone (group 1) was greater than in the normal transitional epithelium of the untreated control group (group 7). The number of AgNORs in the non-lesional transitional epithelium of groups 5 was significantly lower than that of group 1.

\section{Discussion}

In the present study, dietary exposure of $5 \%$ or $10 \%$ FBRA during the promotion phase of $\mathrm{OH}-\mathrm{BBN}$-induced urinary bladder carcinogenesis significantly inhibited the incidence of the bladder carcinoma. Furthermore, post-initiation feeding of $10 \%$ FBRA significantly suppressed the incidence of bladder preneoplastic lesions (dysplasia and simple hyperplasia) when compared with that of mice given the control diet. FBRA has already been proven to inhibit chemically induced carcinogenesis in colon, liver, and esophagus. These results suggest that FBRA is a candidate chemopreventive agent against carcinogenesis in multiple organs including the urinary bladder.

Several mechanisms by which chemopreventive agents exert their inhibitory effects on tumorigenesis were considered. Cell proliferation plays an important role in multistage carcinogenesis and involves multiple genetic alterations (24). In this study, FBRA inhibited cell proliferation activity of the $\mathrm{OH}-$ BBN-exposed non-lesional urinary bladder epithelium. These results are in line with our earlier studies using different carcinogenesis models (18-20). We found no effect of FBRA on the AgNOR counts in normal tissue (groups 6 and 7). This may imply that FBRA shows modulating effects in epithelium of animals given carcinogens. Our earlier study indicated a step-wise increase of the AgNOR number from histologically normal transitional epithelium through hyperplasia and pre-cancerous lesions (dysplasia) to transitional cell carcinoma in $\mathrm{OH}-\mathrm{BBN}$-induced urinary bladder carcinogenesis (25). Furthermore, some chemopreventive agents reduced AgNOR scores and the development of urinary bladder cancer $(9,26)$. Thus, the inhibition of carcinogeninduced hyper-proliferation of urinary bladder epithelium is also suggested to be one important mechanism of the chemopreventive action of FBRA.

FBRA is a processed food prepared by fermenting brown rice and rice bran with Aspergillus oryzae. The nutritional and sanitary advantages of fermentation are gradually recognized. Fermented soybean paste (miso) and soy sauce (shoyu), which are Japanese traditional foods and prepared by fermenting with Aspergillus oryzae, have been found to be more stable against lipid peroxidation than unfermented soybeans because soybean products fermented with Aspergillus oryzae contain several antioxidants in greater abundance (27). These o-dihydroxyisoflavones, produced from soybean- derived isoflavones by fermentation, are reported to possess greater radical-scavenging, anti-proliferative and antimutagenic activity than the corresponding isoflavone analogs (27-29). Several epidemiological and preclinical studies have suggested the preventive effects of such fermented soybean products on breast (30), stomach (31), and prostate cancer (32). For rice, an ethyl acetate extract of 'kurosu,' a vinegar made from unpolished rice containing rice bran, suppressed colonic preneoplastic lesions and cancer induced by azoxymethane $(33,34)$. Thus, it is possible that FBRA has similar biological aspects to fermented soybeans or kurosu. Furthermore, urinary 8-hydroxydeoxyguanosine ( 8 -OHdG) is considered to be a biomarker of generalized, cellular oxidative stress and linked to degenerative disease including cancer (35). The levels of $8-\mathrm{OHdG}$ in each group were measured in this study, but there was no significant difference among the groups (data not shown). Therefore, further investigation into the mechanistic basis of the chemopreventive action of dietary FBRA is warranted.

In conclusion, we demonstrated that dietary exposure of $5 \%$ or $10 \%$ FBRA during the post-initiation phase inhibits tumor development and cell proliferation in the target epithelium of the mouse model with OH-BBN. FBRA is suggested to be a promising chemopreventive agent against the occurrence of human urinary bladder cancer.

\section{Acknowledgements}

We appreciate the technical assistance of Miss K. Takahashi, secretarial assistance of Miss S. Gotou, and animal care provided by Mr. Y. Kinjou. This work was supported by a Grant-in-Aid from the Ministry of Education, Culture, Sports, Science and Technology and a Grant-in-Aid from the Ministry of Health, Labor and Welfare of Japan.

\section{References}

1. Ferlay J, Bray F, Pisani P and Parkin DM: GloboCan 2000: Cancer incidence, mortality and prevalence worldwide. IARC Press, Lyon, 2001

2. Parkin DM, Whelan SL, Ferlay J, Teppo L and Thomas DB: Cancer incidence in five continents. Vol. VIII. IARC Scientific Publications no. 155. IARC Press, Lyon, 2003.

3. Parkin DM, Muir CS, Whelan SL, Gao YT, Ferlay J and Powell J: Cancer incidence in five continents. Vol. VI. IARC Scientific Publications no. 120. IARC Press, Lyon, 1992.

4. Green DF, Robinson MR, Glashan R, Newling D, Dalesio O and Smith PH: Does intravesical chemotherapy prevent invasive bladder cancer? J Urol 131: 33-35, 1984.

5. Lutzeyer W, Rubben $\mathrm{H}$ and Dahm $\mathrm{H}$ : Prognostic parameters in superficial bladder cancer: an analysis of 315 cases. J Urol 127: 250-252, 1982.

6. Kakizoe T, Tobisu K, Tanaka Y, Mizutani T, Teshima SC, Kishi K and Tsutsumi M: Development of multiple transitional cell carcinomas in the urinary tract. Jpn J Clin Oncol 21: 110-114, 1991.

7. Kelloff GJ, Boone CW, Malone WF, Steele VE and Doody LA: Development of chemopreventive agents for bladder cancer: J Cell Biochem Suppl 16I: 1-12, 1992

8. Hirose Y, Tanaka T, Kawamori T, Ohnishi M, Makita H, Mori H, Satoh K and Hara A: Chemoprevention of urinary bladder carcinogenesis by the natural phenolic compound protocatechuic acid in rats. Carcinogenesis 16: 2337-2342, 1995

9. Tanaka T, Morishita Y, Suzui M, Kojima T, Okumura A and Mori H: Chemoprevention of mouse urinary bladder carcinogenesis by the naturally occurring carotenoid astaxanthin. Carcinogenesis 15: 15-19, 1994. 
10. Middleton E Jr, Kandaswami C and Theoharides TC: The effects of plant flavonoids on mammalian cells: implications for inflammation, heart disease, and cancer. Pharmacol Rev 52: 673-751, 2000.

11. Kakizoe T: Chemoprevention of cancer - focusing on clinical trials. Jpn J Clin Oncol 33: 421-442, 2003.

12. Taniguchi H, Hosoda A, Tsuno T, Maruta Y and Nomura E: Preparation of ferulic acid and its application for the synthesis of cancer chemopreventive agents. Anticancer Res 19: 3757-3761, 1999.

13. Graf E, Empson KL and Eaton JW: Phytic acid. A natural antioxidant. J Biol Chem 262: 11647-11650, 1987.

14. Xu Z, Hua N and Godber JS: Antioxidant activity of tocopherols, tocotrienols, and gamma-oryzanol components from rice bran against cholesterol oxidation accelerated by 2,2 '-azobis(2methylpropionamidine) dihydrochloride. J Agric Food Chem 49: 2077-2081, 2001

15. Lamm DL, Riggs DR, Shriver JS, Van Gilder PE, Roch JF and DeHaven JI: Megadose vitamins in bladder cancer: a doubleblind clinical trial. J Urol 151: 21-26, 1994

16. Kawabata K, Tanaka T, Murakami T, Okada T, Murai H, Yamamoto T, Hara A, Shimizu M, Yamada Y, Matsunaga K, Kuno T, Yoshimi N, Sugie S and Mori H: Dietary prevention of azoxymethane-induced colon carcinogenesis with rice germ in F344 rats. Carcinogenesis 20: 2109-2115, 1999.

17. Mori H, Kawabata K, Yoshimi N, Tanaka T, Murakami T, Okada T and Murai H: Chemopreventive effects of ferulic acid on oral and rice germ on large bowel carcinogenesis. Anticancer Res 19: 3775-3778, 1999.

18. Katyama M, Yoshimi N, Yamada Y, Sakata K, Kuno T, Yoshida K, Qiao Z, Vihn PQ, Iwasaki T, Kobayashi H and Mori H: Preventive effect of fermented brown rice and rice bran against colon carcinogenesis in male F344 rats. Oncol Rep 9: 817-822, 2002.

19. Katayama M, Sugie S, Yoshimi N, Yamada Y, Sakata K, Qiao Z, Iwasaki T, Kobayashi $\mathrm{H}$ and Mori H: Preventive effect of fermented brown rice and rice bran on diethylnitrosoamine and phenobarbital-induced hepatocarcinogenesis in male F344 rats Oncol Rep 10: 875-880, 2003.

20. Kuno T, Hirose Y, Hata K, Kato K, Qiang SH, Kitaori N, Hara A, Iwasaki T, Yoshimura T, Wada K, Kobayashi $\mathrm{H}$ and Mori $\mathrm{H}$ : Preventive effect of fermented brown rice and rice bran on $\mathrm{N}$ nitrosomethylbenzylamine-induced esophageal tumorigenesis in rats. Int J Oncol 25: 1809-1815, 2004

21. Tazawa K, Naoko F and Namikawa H: Superoxide scavenging effect of fermented brown rice determined by ESR spin-tapping method (in Japanese). Food Style 3: 32-37, 1999.

22. Mitsuhashi M, Wanibuchi H, Morimura K, Doi K, Wei M, Wada S, Nakatani T and Fukushima S: Significance of overexpression of metallothionein in mouse urinary bladder focal lesions induced by treatment with $N$-butyl- $N$-(4-hydroxybutyl)nitrosamine. Cancer Sci 94: 1052-1058, 2003.

23. Tanaka T, Takeuchi T, Hara A, Ohno T, Kojima T, Morishita Y, Mori Y, Kawada Y, Mori H and Inaba S: Computer-assisted image analysis of silver-positive nucleolar organizer regions in preneoplastic lesions of the liver and urinary bladder induced by carcinogens in rats (in Japanese). J Clin Exp Med 154: 81-82, 1990.
24. Cohen SM and Ellwein LB: Cell proliferation in carcinogenesis. Science 249: 1007-1011, 1990

25. Takeuchi T, Tanaka T, Ohno T, Yamamoto N, Kobayashi S, Kuriyama M, Kawada Y and Mori H: Nucleolar organizer regions in rat urinary bladder tumors induced by $N$-butyl- $N$-(4hydroxybutyl)nitrosamine. Virchows Arch B Cell Pathol Incl Mol Pathol 58: 383-387, 1990.

26. Yang M, Tanaka T, Hirose Y, Deguchi T, Mori H amd Kawada Y: Chemopreventive effects of diosmin and hesperidin on $N$-butyl$\mathrm{N}$-(4-hydroxybutyl)nitrosamine-induced urinary-bladder carcinogenesis in male ICR mice. Int J Cancer 73: 719-724, 1997.

27. Esaki H, Kawakishi S, Morimitsu Y and Osawa T: New potent antioxidative o-dihydroxyisoflavones in fermented Japanese soybean products. Biosci Biotechnol Biochem 63: 1637-1639, 1999.

28. Hirota A, Taki S, Kawaii S, Yano M and Abe N: 1,1-Diphenyl2-picrylhydrazyl radical-scavenging compounds from soybean miso and antiproliferative activity of isoflavones from soybean miso toward the cancer cell lines. Biosci Biotechnol Biochem 64: $1038-1040,2000$

29. Chen YC, Inaba M, Abe $\mathrm{N}$ and Hirota A: Antimutagenic activity of 8-hydroxyisoflavones and 6-hydroxydaidzein from soybean miso. Biosci Biotechnol Biochem 67: 903-906, 2003.

30. Ohta T, Nakatsugi S, Watanabe K, Kawamori T, Ishikawa F, Morotomi M, Sugie S, Toda T, Sugimura T and Wakabayashi K: Inhibitory effects of bifidobacterium-fermented soy milk on 2amino-1-methyl-6-phenylimidazo[4,5-b]pyridine-induced rat mammary carcinogenesis, with a partial contribution of its component isoflavones. Carcinogenesis 21: 937-941, 2000.

31. Ohara M, Lu H, Shiraki K, Ishimura Y, Uesaka T, Katoh O and Watanabe $\mathrm{H}$ : Inhibition by long-term fermented miso of induction of gastric tumors by $N$-methyl- $N$ '-nitro-N-nitrosoguanidine in CD (SD) rats. Oncol Rep 9: 613-616, 2002

32. Sonoda T, Nagata Y, Mori M, Miyanaga N, Takashima N, Okumura K, Goto K, Naito S, Fujimoto K, Hirao Y, Takahashi A, Tsukamoto T, Fujioka T and Akaza H: A case-control study of diet and prostate cancer in Japan: possible protective effect of traditional Japanese diet. Cancer Sci 95: 238-242, 2004.

33. Shimoji Y, Sugie S, Kohno H, Tanaka T, Nanda K, Tamura Y, Nishikawa Y, Hayashi R, Uenakai K and Ohigashi H: Extract of vinegar 'kurosu' from unpolished rice inhibits the development of colonic aberrant crypt foci induced by azoxymethane. J Exp Clin Cancer Res 22: 591-597, 2003.

34. Shimoji Y, Kohno H, Nanda K, Nishikawa Y, Ohigashi H, Uenakai $\mathrm{K}$ and Tanaka $\mathrm{T}$ : Extract of kurosu, a vinegar from unpolished rice, inhibits azoxymethane-induced colon carcinogenesis in male F344 rats. Nutr Cancer 49: 170-173, 2004.

35. Chiou CC, Chang PY, Chan EC, Wu TL, Tsao KC and Wu JT: Urinary 8-hydroxydeoxyguanosine and its analogs as DNA marker of oxidative stress: development of an ELISA and measurement in both bladder and prostate cancers. Clin Chim Acta 334: 87-94, 2003 